\title{
THE OXYGEN SATURATION OF HEMOGLOBIN IN THE ARTERIAL BLOOD OF EXERCISING PATIENTS
}

\author{
BY HAROLD E. HIMWICH AND ROBERT O. LOEBEL
}

(From the Russell Sage Institute of Pathology in Affiliation with the Second Medical (Cornell) Division and the Pathological Department of Belleoue Hospital and the Department of Medicine, Cornell University Medical College, New York)

(Received for publication August 22, 1927)

The following data are presented at the present time even though they are incomplete, since circumstances necessitated an interruption of the work.

Observations of Himwich and Barr (1) on the variations in oxygen content and oxygen capacity which occurred in the arterial blood of normal individuals as a result of exercise indicated that the oxygen saturation of the hemoglobin was increased by moderate exercise of short duration. If, however, the exercise was continued to the point of exhaustion, the saturation of hemoglobin might diminish. A similar decrease was noted by Harrop (2) in a convalescent subject, and also in three patients with polycythemia vera (3). A lessened saturation was found by Barcroft and others (4) when exercise was performed at high altitudes.

An explanation of these varying results was attempted. Though the saturation of hemoglobin in the lungs is influenced by many factors, it is in the last analysis determined by two only; the amount of oxygen diffusing through the pulmonary membrane and the volume of blood flow in the pulmonary circuit; the degree of saturation varying directly with the total amount of oxygen diffusing and inversely with the volume of the circulation. It was proposed that in moderate exercise of normal individuals, at sea level, the amount of oxygen diffusing is more than sufficient to compensate for the increasing circulation rate. However, when the exertion is of an exhausting character, the volume of blood flow may increase to an extent proportionately greater than the increase in oxygen diffusion. It is the purpose of this study to follow the variations in the saturation of 
hemoglobin occurring in the lungs when the various factors involved in the process are changed by disease.

\section{EXPERIMENTAL}

The present report is concerned with the response of several abnormal individuals to exercise. Nine patients were studied, one with

TABLE 1

Oxygen content, oxygen capacity, and saturation of hemoglobin, before, during and after short periods of exercise in patients

\begin{tabular}{|c|c|c|c|c|c|c|c|c|}
\hline \multirow{2}{*}{ Disease } & \multirow{2}{*}{ Patient } & \multirow{2}{*}{ Date } & \multicolumn{2}{|c|}{$\begin{array}{l}\text { Oxygen } \\
\text { content of } \\
\text { arterial } \\
\text { blood }\end{array}$} & \multicolumn{2}{|c|}{$\begin{array}{c}\text { Oxygen } \\
\text { capacity } \\
\text { of arterial } \\
\text { blood }\end{array}$} & \multicolumn{2}{|c|}{$\begin{array}{c}\text { Percentage } \\
\text { saturation } \\
\text { of hemo- } \\
\text { globin }\end{array}$} \\
\hline & & & 竞 & 离 & 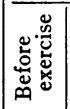 & 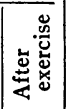 & 总 & 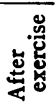 \\
\hline \multirow{2}{*}{ Diabetes. } & William R. & October 31, 1922 & 17.4 & 19.1 & 18.3 & 21.1 & 95 & 90 \\
\hline & William R. & November 16, 1922 & 19.3 & 21.1 & 20.6 & 21.5 & 94 & 98 \\
\hline \multirow{5}{*}{ Anemia. } & John O'R. & July 26, 1923 & 15.0 & 15.3 & 15.6 & 17.1 & 96 & 89 \\
\hline & John O'R. & August 2, 1923 & 16.1 & 16.6 & 17.0 & 18.2 & 95 & 91 \\
\hline & Antonia $\mathrm{O}$. & August 29, 1923 & 8.7 & 9.7 & 9.1 & 10.5 & 96 & 92 \\
\hline & Patrick M. & July 31,1923 & 6.1 & 5.5 & 6.3 & 6.3 & 97 & 87 \\
\hline & Patrick M. & August 7, 1923 & 5.6 & 4.8 & 5.6 & 6.1 & 100 & 79 \\
\hline \multirow{2}{*}{ Cardiac. } & Tony G. & August 10, 1923 & 17.7 & 18.7 & 19.3 & 20.7 & 92 & 90 \\
\hline & Tony G. & August 20, 1923 & 17.8 & 18.3 & 18.5 & 21.3 & 96 & 86 \\
\hline \multirow{3}{*}{ Emphysema. } & William Ru. & July 19, 1923 & 20.3 & 21.3 & 21.4 & 22.5 & 95 & 95 \\
\hline & Joseph B. & August 8, 1923 & 19.5 & 19.7 & 20.3 & 21.6 & 95 & 91 \\
\hline & John L. & August 9, 1923 & 17.5 & 5.2 & 22.4 & 22.6 & 78 & 23 \\
\hline Tuberculosis. & Santos C. & August 3, 1923 & 12.5 & 12.3 & 13.2 & 14.6 & 93 & 84 \\
\hline
\end{tabular}

diabetes, three with anemia, one with auricular fibrillation before and after the normal heart rhythm had been restored by quinidin, three with varying degrees of emphysema and one with chronic pulmonary tuberculosis and secondary anemia. In all, thirteen observations were made. Protocols of the analyses and case records may be found at the end of the paper. The procedures and technique were similar to those employed in the experiments of Barr, Himwich and Green 
(5). All work was done on a bicycle ergometer about four hours after a light breakfast. One brachial artery was punctured about two minutes before exercise, the other about an equal length of time after the work was completed. The blood was analyzed for oxygen content and capacity by the method of Van Slyke and Stadie (6). The error of the method is 0.5 volumes per cent. The results are given in table 1.

Diabetes. The two observations were done incidentally in the course of other work and are mentioned as evidence concerning the reaction of debilitated individuals to exertion and not in any sense as examples of a specific effect of diabetes. In William $R$. there was no

TABLE 2

Oxygen content, oxygen capacity, and saturation of hemoglobin, before, during and after short periods of exercise in normal individuals

\begin{tabular}{|c|c|c|c|c|c|c|c|c|c|c|}
\hline \multirow{2}{*}{ Subject } & \multirow{2}{*}{ Date } & \multicolumn{3}{|c|}{$\begin{array}{l}\text { Oxygen content } \\
\text { of arterial blood }\end{array}$} & \multicolumn{3}{|c|}{$\begin{array}{l}\text { Oxygen capacity } \\
\text { of arterial blood }\end{array}$} & \multicolumn{3}{|c|}{$\begin{array}{l}\text { Percentage of } \\
\text { saturation of } \\
\text { hemoglobin }\end{array}$} \\
\hline & & 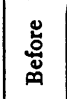 & 葛 & $\stackrel{\Xi}{4}$ & 芯 & 泀 & $\underset{\mathbb{S}}{4}$ & 荧 & 总 & $\stackrel{\text { 峞 }}{4}$ \\
\hline & $\begin{array}{r}1922 \\
\text { Aurust } 8\end{array}$ & 197 & & $\begin{array}{lll}21 & 4\end{array}$ & 205 & & {$\left[\begin{array}{lll}0 & 0\end{array}\right.$} & 96 & & 08 \\
\hline $\begin{array}{l}\text { D. P. B.... } \\
\text { H. E. H... }\end{array}$ & August 10 & 18.0 & 19.7 & 19.7 & $\begin{array}{l}20.0 \\
19.1\end{array}$ & 20.0 & 20.2 & 94 & 99 & $\begin{array}{l}00 \\
98\end{array}$ \\
\hline D. P. B.. & August 15 & 19.9 & & $22.7 \mid$ & 21.3 & & $23.8 \mid$ & 94 & & 95 \\
\hline D. P. B... & October 17 & 20.6 & & 22.7 & 22.1 & & $23.7 \mid$ & 93 & & 96 \\
\hline H. E. H... & October 27 & 20.0 & 21.2 & 20.9 & 21.1 & & 21.6 & 95 & & 97 \\
\hline
\end{tabular}

external evidence of cardiac or respiratory disease at the time of either observation. The general physical condition, however, varied greatly on the two days of experimentation. On October 31st the exercise was done at a time when he was physically weak, and there was much sugar (28 grams in 24 hours) in his urine. At this time the saturation of hemoglobin in his arterial blood was slightly diminished as the result of work. In the second experiment (November 16th) his health had improved and all sugar had disappeared from his urine. Although the amount of work was greater, he reacted like a normal person with a slight increase in hemoglobin saturation after the exertion. 
Anemia. In considering the results in anemic patients it must be remembered that with blood of low oxygen capacity the effect of any error in analysis is exaggerated. The chance of gaining a false impression from a limited number of observations is therefore greater with anemic blood than with normal. Nevertheless it is surprising to find that there was, in every observation in anemic persons, a diminuation of the saturation of hemoglobin of the arterial blood following exercise. This was slight in two patients but was marked in both observations of the third.

Auricular fibrillation. Two observations were made on Tony G. During the first the patient's heart was fibrillating. He did moderately severe work for two minutes with no essential change in the oxygen saturation of hemoglobin in the arterial blood. Ten days later an equal amount of work was done when conditions were apparently similar except that as a result of quinidin therapy the patient's heart was regular. In the second observation there was a distinct fall in the saturation of hemoglobin.

Tuberculosis. Santos C. had an extensive fibroid pulmonary tuberculosis involving the entire left lung and the upper lobe of the right. He also had a marked secondary anemia (12.5 volumes per cent oxygen capacity). While resting, the saturation was normal, within the limits of error, 93 per cent. After a moderate amount of exertion, the arterial saturation was only 84 per cent.

Emphysema. None of the three subjects had any obvious circulatory difficulty at the time of the observtions. William R. had a definite though not very severe type of emphysema. During rest the saturation of hemoglobin of arterial blood was normal, a condition which was not changed by a moderate amount of exercise. Joseph B. had a more obvious emphysema, but while resting had a normal saturation of hemoglobin. Following a smaller amount of work the saturation was diminished.

John L. was suffering from a more advanced degree of emphysema. At rest he was cyanotic. Dyspnea was apparent both in inspiration and in expiration. In three different samples taken at rest the saturation of hemoglobin in his arterial blood was approximately 80 per cent. With a small amount of exercise (only 1594 kilogram meters in $3 \frac{1}{2}$ minutes), a remarkable result was obtained. The hemoglobin 
saturation of the arterial blood fell from 78 per cent while resting to 23 per cent 1 to 2 minutes after exercise. The oxygen content of arterial blood fell from 17.5 to 5.2 volumes per cent. The resting arterial hemoglobin saturation in this patient was about that of normal mixed venous blood while the arterial saturation after exercise was far below any values previously reported.

Table 2 presents the results on normal individuals and is reproduced here for comparison. The saturation of hemoglobin increased in exercise. It is apparent that the patients reacted in a manner different from that of normal persons. Though only a few patients were studied and the variations in the saturation of hemoglobin before and after exercise were small, still it may be stated that in diseased subjects the saturation fell after exercise.

In attempting to throw light on the mechanisms involved in producing these changes it may be pointed out that in the tuberculous subject and in the patient with the advanced emphysema there must obviously have been difficulty in the diffusion of gases in the lungs which would lead to incomplete saturation of the hemoglobin of the blood in the lungs. In Harrop's patients (3) with polycythemia vera no abnormalities in the lungs were found on physical examination but he was able to determine a decreased permeability of the alveolar membrane to gases which he considered a probable cause for the diminished saturation of hemoglobin after exercise.

In the patient with cardiac decompensation many factors may have been instrumental in producing the final result. Pulmonary congestion and other factors might interfere with diffusion in the lungs thus diminishing the saturation of hemoglobin while a slower circulation rate might have the reverse effect (Lundsgaard (7), Blumgart and Weiss (8) ). It seems possible that the decreased saturation of the hemoglobin with work, after quinidin therapy, may have been due to an increased circulation rate on the restoration of the normal rhythm of the heart. In the observation on the diabetic when severely ill and on the anemic patients, due to lack of evidence of definite changes in the lungs, the lowered saturation of hemoglobin is imputed to the same condition which causes a decreased saturation of hemoglobin on exhausting exertion of normal subjects; namely, an increase in the circulation rate when the volume of oxygen diffusing through 
the pulmonary membrane has reached a maximum. The genesis of this condition was considered in the previous paper (1). It may suffice to say here that one of the factors causing increased diffusion of oxygen in the lungs is a decrease in oxygen tension of the venous blood and the latter must speedily come to its lower limit during exercise for even at rest the venous blood is quite unsaturated in severe anemia (Lundsgaard (9), Barr and Peters (10)).

An increased amount of oxygen in the inspired air might have raised the saturation of hemoglobin in the arterial blood of the patients during exercise and thus have produced a beneficial effect. Perhaps the situation here is similar to that observed by Briggs (11) who noted that the endurance of untrained man was increased on breathing oxygen while oxygen was of little aid to the trained athlete unless he carried exertion to the point of exhaustion. Perhaps in the untrained man, as in the sick subject, circulation rate is increased disproportionately to the volume of oxygen diffusing in the lungs.

\section{SUMMARY AND CONCLUSIONS}

1. Thirteen observations have been made during rest and after exertion on nine patients suffering from a variety of pathological conditions.

2. As a result of exercise, in eleven observations, there was a diminution in the degree of saturation of the hemoglobin in the arterial blood. In a patient with severe emphysema, the saturation fell from 78 per cent to 23 per cent with only slight exertion. In five of these eleven observations the oxygen content of arterial blood remained stationary or was diminished in spite of an increase in oxygen capacity.

3 . These results are directly opposed to those upon normal individuals who, doing equal or greater amounts of work, have always shown an increased saturation of hemoglobin with oxygen and a higher arterial oxygen content, but are similar to those obtained with normal individuals doing much longer and more fatiguing amounts of work.

4. The experiments indicate that in ill and debilitated individuals during exertion the volume of oxygen diffusing through the pulmonary membrane is not enough to saturate the hemoglobin of the blood in the lungs. This suggests that the pulmonary mechanism may be a limiting factor in exercise - a factor which explains in part the inability of sick people to withstand exertion. 


\section{BIBLIOGRAPHY}

1. Himwich, H. E., and Barr, D. P., J. Biol. Chem., 1923, lvii, 363. Studies in the Physiology of Muscular Exercise. V. Oxygen Relationships in the Arterial Blood.

2. Harrop, G. A., Jr., J. Exp. Med., 1919, xxx, 341. The Oxygen and Carbon Dioxide Content of Arterial and of Venous Blood in Normal Individuals and in Patients with Anemia and Heart Disease.

3. Harrop, G. A., Jr., Heath, E. H., and Schaub, B. M., J. Clin. Invest., 1927, iv, 53. Pulmonary Gas Diffusion in Polycythemia Vera.

4. Barcroft, J., Cooke, A., Hartridge, H., Parsons, T. R., and Parsons, W., J. Physiol., 1920, liii, 450. The Flow of Oxygen through the Pulmonary Epithelium.

5. Barr, D. P., Himwich, H. E., and Green, R. P., J. Biol. Chem., 1923, lv, 495. Studies in the Physiology of Muscular Exercise. 1. Changes in Acid-Base Equilibrium following Short Periods of Vigorous Muscular Exercise.

6. Van Slyke, D. D., and Stadie, W. C., J. Biol. Chem., 1921, xlix, 1. The Determination of Gases in the Blood.

7. Lundsgaard, C., Deutsch. Arch. klin. Med., 1916, cxviii, 513. Untersuchungen über das Minutenvolumen des Herzens bei Menschen. II.

8. Blumgart, H. L., and Weiss, S., J. Clin. Invest., 1927, iv, 173. Studies on the Velocity of Blood Flow. IV. The Velocity of Blood Flow and its Relation to Other Aspects of the Circulation in Patients with Arteriosclerosis and in Patients with Arterial Hypertension.

9. Lundsgaard, C., J. Exp. Med., 1919, xxx, 147. Studies of Oxygen in the Venous Blood. V. Determinations in Patients with Anemia.

10. Barr, D. P., and Peters, J. P., J. Biol. Chem., 1921, xlv, 571. The Carbon Dioxide Absorption Curve and Carbon Dioxide Tension of the Blood in Severe Anemia.

11. Briggs, H., J. Physiol., 1920, liv, 292. Physical Exertion, Fitness and Breathing.

\section{CASE RECORDS}

Case 1. William R. Moderate diabetes. Age 29 years. Grocer's clerk. First noticed symptoms in July, 1922, when sugar was found in urine. Lost 40 pounds from July to October, 1922. On admission October 2nd his weight was 98 pounds. Urine examination showed sugar ++++ , and a trace of diacetic acid. Except for emaciation physical examination was negative. Blood sugar on admission was $464 \mathrm{mg}$. per cent. On October 30th, diet supposedly was carbohydrate 15 grams, protein 15 grams, fat 90 grams, but the patient undoubtedly was breaking diet. Twenty-four hour urine contained 28.0 grams of sugar. Reaction to exercise studied October 31st. On November 5th, was transferred to metabolism ward where conditions were carefully controlled. Diet from November 5 th to 10 th, carbohydrate 15 grams, protein 15 grams, fat 90 grams; sugar in 


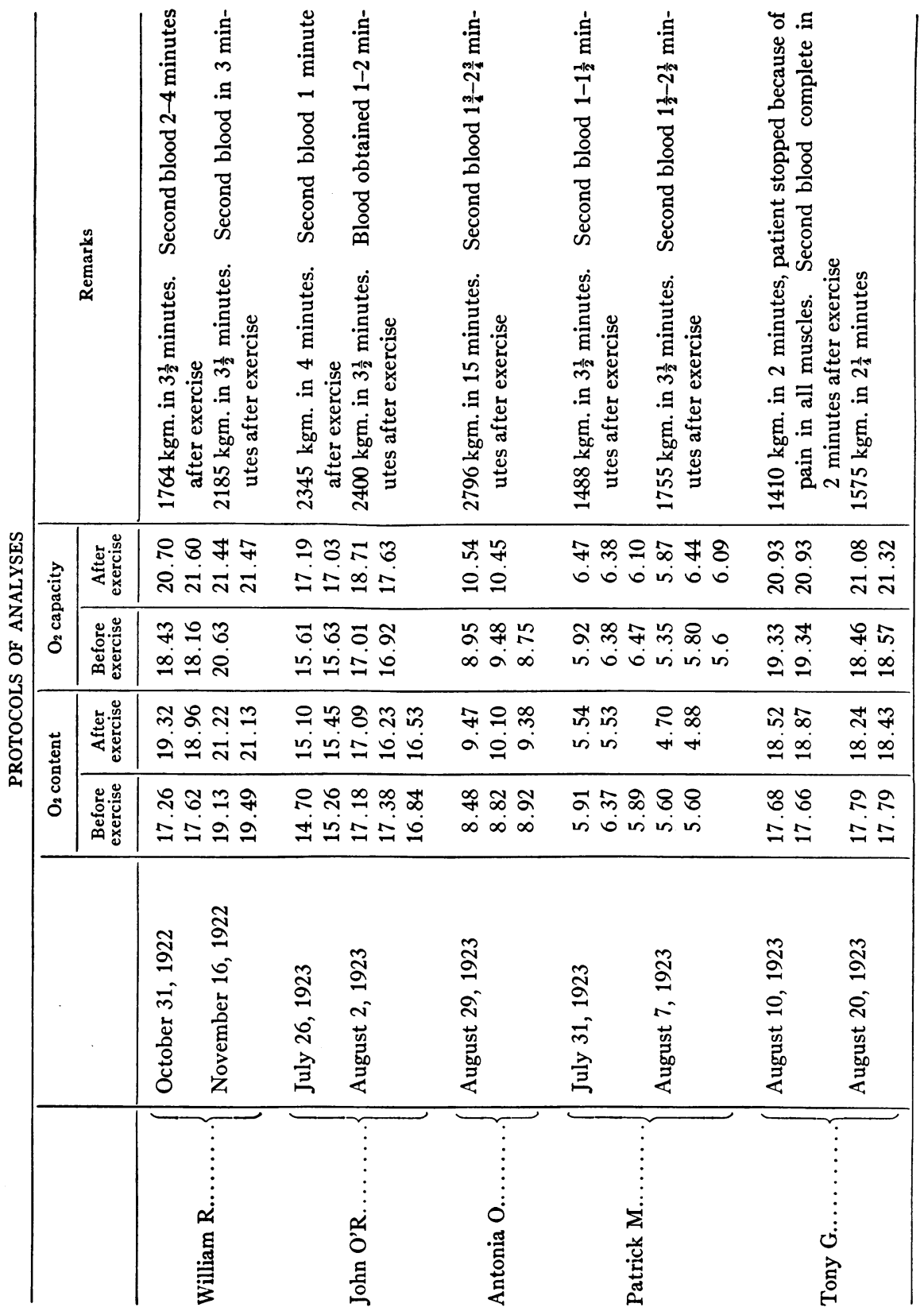




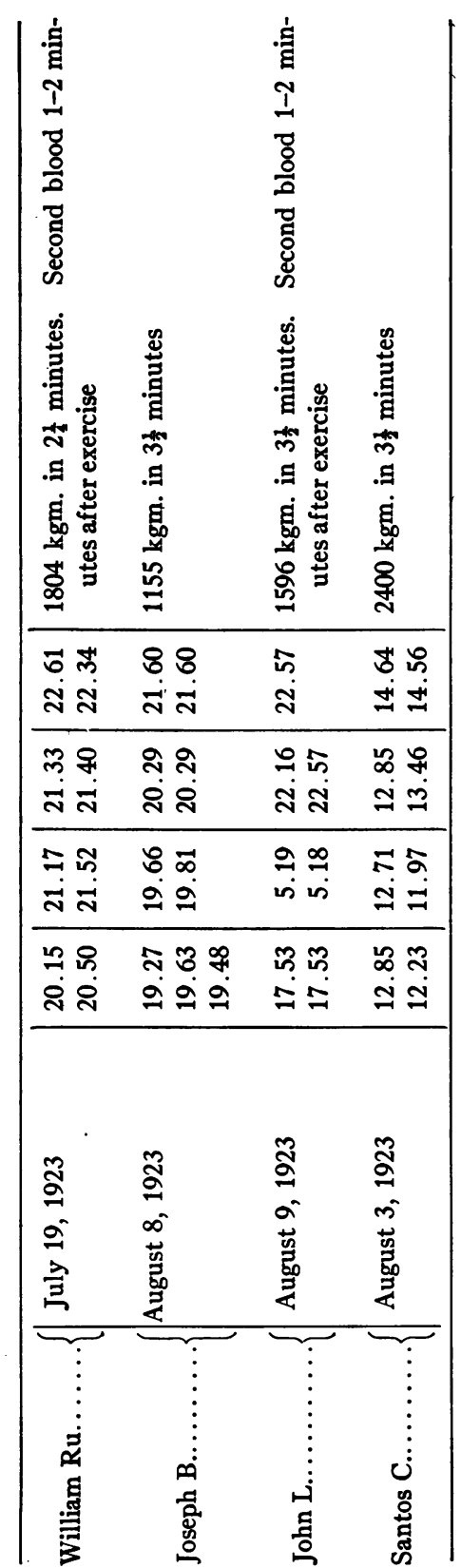


24-hour specimen fell from 96.5 grams on November 6th to a trace on November 10th. Total acetone in urine fell from 8.8 grams on November 6 th to 3.2 grams on November 10th.

Case 2. John O'R. Possible pernicious anemia. Age 55 years. Policeman. Six weeks before admission had noticed dizziness, weakness, dyspnea on exertion, indigestion (retching), and yellow color of face and loss of 20 pounds. Previously he had always been athletic. Admitted June 6, 1922. Physical examination revealed a well-developed man with pasty color of face and pale mucous membranes. Chest showed no abnormality. Arteries were slightly thickened. Test meal disclosed no free hydrochloric acid in stomach. X-ray examination of gastrointestinal tract was negative. Stools negative for blood, and Wassermann negative. Red blood cells 1,184,000. Hemoglobin 36 per cent at time of admission. On Ju'y 24th hemoglobin was 60 per cent. First reaction to exercise was studied on July 26th. On July 30th, hemoglobin was 75 per cent, and on August 2nd, second observation on exercise was made. At time of observation, weight was $69.4 \mathrm{~kg}$. and height $185 \mathrm{~cm}$. West's factor, surface area in health $\times 2.5$, was used for calculating the vital capacity (see West, H. F., Arch. Int. Med., 1920, xxv, 306). Calculated vital capacity, 5250 cc. Observed vital capacity, 4800 cc.

Case 3. Antonia O. Banti's disease? Age 32. Native of Uruguay. History of excessive use of alcohol. Chief complaints were weakness and vomiting of blood which began one year ago. Since admission (June 6,1923) had brought up coffee-grounds vomitus twice and passed both bright and dark colored blood in stools. Red blood cells 1,500,000. Hemoglobin (Tallquist) 20 per cent. Physical examination-mucous membranes pale; heart normal except for blowing systolic murmur. Blood pressure $92 \mathrm{~mm}$. mercury systolic, $44 \mathrm{~mm}$. mercury diastolic. Liver was two inches below costal margin, firm and not tender. On August 27th, 8 quarts ascitic fluid were removed from abdomen. On August 29th, exercised on bicycle ergometer. Weight $62.4 \mathrm{~kg}$. Height $166 \mathrm{~cm}$. Calculated vital capacity $4230 \mathrm{cc}$. Observed vital capacity $3200 \mathrm{cc}$.

Case 4. Patrick M. Perniciousanemia. Age 62. Born in Ireland. Gradual onset of dyspnea on exertion, weakness, loss of appetite. At time of observation there was intermittent epigastric pain, insomnia and nocturia three to five times. Best weight 184 pounds. Physical examination-pale yellow skin, short thickset man with prognathous jaw. Chest well developed. Heart negative except for short blowing systolic murmur not transmitted. Pulse rate varied from 70 to 90 per minute. X-ray of chest was negative. Blood picture, June 5th, red blood cells, 2,400,000. Hemoglobin (Tallquist) 35 per cent. White blood cells 8,500. Blood pressure $110 \mathrm{~mm}$. systolic, $80 \mathrm{~mm}$. diastolic. Reaction to exercise studied July $31 \mathrm{st}$ and August 7th. Weight, $71.6 \mathrm{~kg}$. Height, $166 \mathrm{~cm}$. Calculated vital capacity, 4500 cc. Observed vital capacity, 3400 cc. 
Case 5. Tony. G. Auricular fibrillation. Spaniard, age 30. On April 7th was admitted into hospital with lobar pneumonia. Left hospital cured in eighteen days. After working for two weeks noticed that his heart was very rapid and was forced to stop work because of pain down left arm. On readmission June 18th, heart was regular at 150 beats per minute, and generally enlarged with point of maximum impulse in sixth intercostal space. Electrocardiogram disclosed no abnormality except tachycardia. On July 9 th heart became completely irregular. Patient was readmitted August 2nd with a wholly irregular heart and a pulse deficit. Reaction to exercise studied August 10th. August 18th quinidin therapy was started. On August 19th had palpitation for two hours following which there was sudden return to regular rhythm of the heart at rate of 100 . The patient had received 2.4 grams of quinidin by August 20th and his pulse was regular at 69 beats per minute. Reaction to exercise was studied on this day. Weight $86.7 \mathrm{~kg}$. Height $160 \mathrm{~cm}$. Calculated vital capacity, $4750 \mathrm{cc}$. Observed vital capacity before and after quinidin $3500 \mathrm{cc}$.

Case 6. Santos C. Chronic pulmonary tuberculosis. Age 28. Two years ago began coughing and glands in left axilla became swollen. On operation they were found to be tuberculous. Three months later glands in neck became swollen. Two months ago there began hemoptysis, night sweats, pain over left chest, dyspnea on exertion. Was admitted to hospital June 18th with enlarged glands in left axilla and neck and discharging sinuses. At this time afebrile pulse rate varied between 80 and 88 beats per minute. Physical and $x$-ray examinations revealed fibrosis and infiltration throughout entire left lung and fibrosis of right upper lobe. Blood picture; red blood cells 4,240,000; hemoglobin 65 per cent. Weight $69.0 \mathrm{~kg}$. Height $181.5 \mathrm{~cm}$. Calculated vital capacity, $4750 \mathrm{cc}$. Observed vital capacity, $3200 \mathrm{cc}$.

Case 7. William Ru. Angina pectoris, mild diabetes and emphysema of four years duration. Age 53. Entered hospital July 13th, 1923, because of anginal attack of one week's duration, with pain radiating down left arm. While in hospital, routine examination of urine disclosed diabetes of mild degree. Sugar ,++ no acetone, nor diacetic acid in urine. Sugar in blood $200 \mathrm{mg}$. Carbon dioxide combining power of plasma 45 volumes per cent. Both the angina and the evidences of diabetes rapidly subsided: The patient's reaction to exercise was studied July 19,1923. On physical examination the patient was slightly dyspneic and orthopneic. The chest was large and barrel-shaped, hyperresonant to percussion. The breath sounds were obscured by long musical murmurs and expiration was difficult and prolonged. Fluoroscopic examination showed a normal arch and a heart enlarged to right and left. The lungs were negative and the costophrenic sinus was clear. Weight $76 \mathrm{~kg}$. Height $169.5 \mathrm{~cm}$. Calculated vital capacity 4680 cc. Observed vital capacity 2900 cc. 
Case 8. Joseph B. Emphysema. Age 43. Emphysema(?) starting at age of 23. Asthmatic attacks for five years, better in summer, worse in winter; caught cold easily and was sensitive to chicken feathers. Patient was short and obese with cyanosed face, hands and feet, and an expiratory dyspnea. Chest was large, hyperresonant with sibilant and sonorous rhonchi. Vocal fremitus was transmitted to surface of chest. Sputum contained eosinophiles and no acid-fast bacilli. X-ray of chest showed sclerosis of aortic arch and heart enlargement to left; emphysema; no tuberculosis. Weight $86.7 \mathrm{~kg}$., Height $160 \mathrm{~cm}$. Calculated vital capacity, $5220 \mathrm{cc}$. Observed vital capacity, $1700 \mathrm{cc}$.

Case 9. John L. Emphysema. Age 49. For last 13 years there was increasing dyspnea especially on exertion and a loss of 32 pounds in weight. Patient was a heavy drinker and smoker. Physical examination disclosed marked cyanosis of lips and fingers, orthopnea and dyspnea which was both expiratory and inspiratory. Accessory muscles of respiration were used but chest expansion was very poor and chest wall was rigid. The chest was hyperresonant. Vocal fremitus and voice sounds were transmitted to surface of chest and breath sounds were poorly heard. There were a few dry râles over chest. Heart; left border fifth intercostal space, $9.5 \mathrm{~cm}$. from midsternal line. Sounds of fair quality and regular. Fluoroscopic and $\mathrm{x}$-ray examination-lungs emphysematous; thorax elevated as one piece; intercostal spaces wide; diaphragm descended slightly on both sides (marked limitation). No evidence of fluid or adhesions or masses in mediastinum. Aorta and heart were normal. Increased fibrous tissue production in bronchial wall. Diagnosis-chronic bronchitis, emphysema. Weight 71.8 kg. Height $183 \mathrm{~cm}$. Calculated vital capacity, $5220 \mathrm{cc}$. Observed vital capacity, $3100 \mathrm{cc}$. 